\title{
ARTIGO
}

\section{DETERMINANTES ENVOLVIDOS NO PERFIL DE DOENÇAS RELACIONADAS ÀS CONDIÇÕES SANITÁRIAS INADEQUADAS NOS MUNICÍPIOS BRASILEIROS: AVALIAÇÃO REALIZADA NAS 10 MELHORES E 10 PIORES CIDADES DO RANKING DO SANEAMENTO ${ }^{1}$}

\author{
Ana Carolina Toledo Rocha ${ }^{2}$ \\ Hygor Aristides Victor Rossoni \\ Marco Túlio da Silva Faria
}

\begin{abstract}
RESUMO
O objetivo do presente estudo foi analisar indicadores demográficos, de desenvolvimento humano, de condições sanitárias e os perfis de doenças - diarreia, dengue e leptospirose com destaque para os 10 melhores e os 10 piores municípios, de acordo com o Ranking do Saneamento elaborado pelo Instituto Trata Brasil. Para isso, foram utilizados dados obtidos pela compatibilização de informações provenientes do Sistema Nacional de Informações sobre Saneamento, do Censo Demográfico e do Departamento de Informática do Sistema Único de Saúde, referentes ao ano de 2015, e do Atlas do Desenvolvimento Humano, referente ao ano de 2013. Verificou-se por meio de testes estatísticos não paramétricos univariados e multivariados, que os municípios mais bem classificados no ranking estão localizados nas regiões sul e sudeste, que são as mais desenvolvidas do Brasil. Além disso, notou-se também que as 10 cidades mais bem classificadas no Ranking do Saneamento possuem melhor qualidade de vida e maior desenvolvimento econômico, dados evidenciados pelo valor do Índice de Desenvolvimento Humano Municipal. Nos aspectos ligados à saúde, observou-se que os 10 piores municípios estão fortemente associados às regiões norte e nordeste e apresentam baixos desempenhos nos indicadores de saneamento, principalmente os associados aos índices relacionados à proporção de esgoto tratado referido a água consumida e aos índices epidemiológicos — diarreia, dengue e leptospirose. Desse modo, percebe-se que a falta ou a existência de serviços de saneamento inadequados provocam a insalubridade ambiental que, por sua vez, favorece a ocorrência de diversas doenças.
\end{abstract}

Palavras-chave: Saneamento. Políticas Públicas. Ranking do Saneamento.

\footnotetext{
${ }^{1}$ Como citar este artigo: ROCHA, Ana Carolina Toledo; ROSSONI, Hygor Aristides Victor; FARIA, Marco Túlio da Silva. Determinantes envolvidos no perfil de doenças relacionadas às condições sanitárias inadequadas nos municípios brasileiros: avaliação realizada nas 10 melhores e 10 piores cidades do ranking do saneamento. ForScience: revista científica do IFMG, Formiga, v. 6, n. 2, e00407, out. 2018. Edição Especial.
}

2 Autor para correspondência: Ana Carolina Toledo Rocha, IFMG - Campus Bambuí e-mail: anacarolinatoledorocha@gmail.com 


\section{INTRODUÇÃO}

A equidade, a integralidade e a universalização do acesso às condições básicas de saneamento são pontos fundamentais para promover a prevenção de doenças e acidentes ambientais (como poluição hídrica e enchentes), a preservação do meio ambiente, a segurança hídrica, o desenvolvimento socioeconômico dos municípios e a redução das desigualdades sociais.

Esses três princípios já estavam presentes no movimento da Reforma Sanitária, na década de 70, e foram descritos no Plano Nacional de Saúde e Ambiente como termos orientadores da integração das ações de ambiente e saúde ao desenvolvimento econômico (BRASIL, 1995). Mas foi só em 2007, com o advento da Lei $\mathrm{n}^{0} 11.445$ (diretrizes nacionais sobre o saneamento básico), que eles foram consolidados, evidenciando o acesso ao saneamento básico como um direito de todos (BRASIL, 2007). De acordo com esta Lei, o saneamento básico é um conjunto de serviços, infraestruturas e instalações operacionais de abastecimento de água potável, esgotamento sanitário, limpeza urbana e manejo de resíduos sólidos e drenagem e manejo de águas pluviais (BRASIL, 2007).

Cabe destacar que somente a existência de serviços de água e esgoto em todas as áreas não é sinônimo de universalização, é preciso que haja qualidade e continuidade nos serviços e acesso à infraestrutura, principalmente na prestação dos serviços que historicamente foram negligenciados, sendo estes o manejo de resíduos sólidos e de águas pluviais, os quais também são fundamentais para assegurar o bem-estar da sociedade.

De acordo com Galvão Jr. (2009), o acesso à infraestrutura de saneamento pode ser um fator limitante, visto que a população com baixo poder aquisitivo pode apresentar dificuldades para pagar as tarifas cobradas. Nesse sentido, o autor defende a implementação de políticas públicas redistributivas e sugere a utilização de subsídios, fundos e recursos a fundo perdido para promover o acesso às infraestruturas de saneamento.

Segundo Heller e Castro (2007), a provisão de serviços de saneamento inclui não só o desenvolvimento de técnicas e o seu uso adequado, como também abrange a esfera das políticas públicas que compreende elaboração, avaliação, organização institucional e participação da sociedade. Assim, os autores definem políticas públicas como "[...] um processo, que envolve decisões por parte de corpos e autoridades governamentais, e ações, realizadas por um ator ou um conjunto de atores, e é composto por metas e os meios para alcançá-la.” (HELLER; CASTRO, 2007, p. 286). 
Galvão Jr. (2009) afirma que a universalização dos serviços de saneamento gera importantes impactos sobre a saúde, o ambiente e a cidadania e, por isso, é um dos objetivos das políticas públicas. $\mathrm{O}$ autor considera ainda que não há uma única solução tecnológica para se alcançar a universalização. Na verdade, é preciso analisar variáveis técnicas, sociais e econômicas para garantir a implantação e a sustentabilidade dos serviços (GALVÃO JR., 2009).

Conforme dados do Sistema Nacional de Informações sobre Saneamento, há cerca de 102 milhões de brasileiros com acesso à coleta dos esgotos $(50,3 \%)$ e apenas $42,7 \%$ dos esgotos gerados no país são tratados (BRASIL, 2017b). Tendo em vista a situação atual brasileira e a importância da universalização do acesso aos serviços de saneamento, verificase a necessidade de políticas públicas eficientes, eficazes e adequadas à realidade local.

Com relação a essas políticas voltadas para o saneamento básico, Leoneti, Prado e Oliveira (2011) afirmam que elas são eficazes para reduzir a mortalidade infantil no período pós-neonatal. Os autores explicam que os óbitos neste período ocorrem, principalmente, em decorrência de doenças associadas às condições ambientais.

A partir da ideia exposta anteriormente, observa-se que saúde e saneamento são duas áreas interligadas e dependentes entre si. Heller e Castro (2007) reconhecem essa relação ao afirmarem que os serviços de saneamento são importantes para a proteção da saúde e para melhorar a qualidade de vida da população.

De acordo com a Organização Mundial da Saúde, a melhoria das condições de saneamento tem um papel fundamental na redução de doenças relacionadas ao saneamento inadequado (SCHERMBRUCKER, 2014). A Organização ainda afirma que para cada dólar investido em água e saneamento, economiza-se cerca de US\$ 4,3 em gastos com a saúde humana, destacando a diarreia, a cólera, a febre tifoide e a hepatite (SCHERMBRUCKER, 2014). Além destas, Almeida e Vermelho (1997) citam ainda a dengue e a leptospirose.

Considerando essa conjuntura, Costa et al. (2005) explicam que a utilização de indicadores epidemiológicos é importante para demonstrar quais são os efeitos do acesso ao saneamento ou da sua insuficiência na saúde humana. Os autores acreditam que tais indicadores são ferramentas imprescindíveis para monitorar os fatores ambientais que afetam a saúde, além de orientar as políticas públicas para o estabelecimento de um saneamento adequado.

Diante desse contexto, o objetivo do presente trabalho foi analisar indicadores demográficos, de desenvolvimento humano, de condições sanitárias e os perfis de doenças - 
diarreia, dengue e leptospirose - dos 10 melhores e dos 10 piores municípios brasileiros, de acordo com o Ranking do Saneamento, elaborado pelo Instituto Trata Brasil.

\section{REFERENCIAL TEÓRICO}

As questões sobre o saneamento básico no Brasil tiveram início no século XVII, com a construção de chafarizes e fontes próprias para o abastecimento de água. Contudo, somente em meados do século XX surgiram ações mais concretas no setor, quando o poder público constatou que a falta de abastecimento de água e esgoto era um dos principais problemas da habitação (CYNAMON, 1986). Diante dessa circunstância, o Banco Nacional da Habitação criou o Plano Nacional de Saneamento (Planasa), cujo objetivo era garantir, até 1980, o abastecimento de água de $80 \%$ da população urbana e de $50 \%$ com serviços de esgoto (TUROLLA, 2002).

Para que isso fosse possível, os municípios deveriam conceder os serviços de saneamento a companhias estaduais, que fariam a execução do plano de forma autofinanciável, ou seja, por meio do retorno de investimentos e por arrecadação de tarifas justas (CYNAMON, 1986). De um modo geral, houve melhoras significativas no setor. Segundo Toneto Jr. e Saiani (2006), a população urbana atendida pelo abastecimento de água passou de 50\% em 1971, para 86\% em 1991. Com relação ao esgotamento sanitário, apenas $24 \%$ da população urbana tinha acesso à rede coletora em 1971, passando para 49\% em 1991 (TONETO JR.; SAIANI, 2006).

Entretanto, devido a dificuldades internas e conjunturais na década de 1980, o Planasa passou por um colapso financeiro (TONETO JR.; SAIANI, 2006). Algumas medidas foram tomadas para tentar superar a crise, como a permissão para que os municípios conseguissem financiamentos para o setor, porém, essas ações não obtiveram sucesso e, em 1992, o Plano foi extinto (SAIANI; TONETO JR., 2010).

Turolla (2002, p. 13) enfatiza que "o Planasa foi o único mecanismo articulado de financiamento e de modernização do setor de saneamento no Brasil’”. O autor ainda explica que a Política Nacional de Saneamento passou toda a década de 1990 sem regulamentação e que as iniciativas governamentais foram pontuais e desarticuladas.

Assim, em 2007, o governo federal instituiu a Lei $\mathrm{n}^{0} 11.445$, que estabelece as diretrizes nacionais para o saneamento básico. Segundo esta Lei, o saneamento básico é o conjunto de serviços, infraestruturas e instalações operacionais de abastecimento de água 
potável, esgotamento sanitário, limpeza urbana e manejo de resíduos sólidos e drenagem e manejo de águas pluviais (BRASIL, 2007).

Além de proporcionar maior bem-estar para a população, um sistema de saneamento adequado contribui para a preservação do meio ambiente, pois evita a contaminação dos solos devido à disposição inapropriada de resíduos sólidos e a poluição de recursos hídricos pelo lançamento inadequado de efluentes líquidos, por exemplo.

Nesse sentido, percebe-se que outras legislações, mesmo que de forma implícita, já orientavam ações em prol da universalização dos serviços de saneamento básico. Ainda em 1981, a Política Nacional do Meio Ambiente, estabelecida pela Lei ${ }^{0}{ }^{6} 6.938$, defendia o desenvolvimento socioeconômico, os interesses de segurança nacional e a proteção à dignidade da vida por meio da preservação, melhoria e recuperação da qualidade ambiental, o que somente seria possível se todas as pessoas tivessem acesso ao saneamento (BRASIL, 1981).

Do mesmo modo, o primeiro objetivo da Política Nacional de Recursos Hídricos, instituída pela Lei $\mathrm{n}^{0}$ 9.433, é “[...] assegurar à atual e às futuras gerações a necessária disponibilidade de água, em padrões de qualidade adequados aos respectivos usos [...]" (BRASIL, 1997, p. 470). Portanto, subtende-se a necessidade dos serviços de saneamento, uma vez que é preciso conservar e proteger os recursos hídricos e tratar as águas residuárias para alcançar tal objetivo.

Por outro lado, o saneamento não tem relação somente com o meio ambiente, sendo também associado à saúde, o que pode ser comprovado na Lei $\mathrm{n}^{\circ} 8.080$, a qual define que um dos fatores determinantes e condicionantes da saúde é o saneamento básico (BRASIL, 1990). Essa mesma Lei cria o Sistema Único de Saúde (SUS), o qual busca, entre outros objetivos, dar “[...] assistência às pessoas por intermédio de ações de promoção, proteção e recuperação da saúde, com a realização integrada das ações assistenciais e das atividades preventivas" (BRASIL, 1990, p. 18055).

Seguindo essa mesma linha, a Assembleia Geral da Organização das Nações Unidas (ONU) aprovou, em julho de 2010, a Resolução n 64/292 que "reconhece o acesso à água potável e ao esgotamento sanitário como um direito humano essencial para desfrutar plenamente a vida e todos os outros direitos humanos" (UN, 2010, p. 2, tradução nossa).

Recentemente, na $36^{\mathrm{a}}$ sessão do Conselho de Direitos Humanos da ONU, ficou reconhecido que a regulamentação dos serviços de água e esgoto é o ponto de partida para 
garantir o direito a um nível de vida adequado, proporcionando o direito à saúde física e mental, à vida e à dignidade humana (UN, 2017).

Essas reuniões internacionais evidenciam a importância do poder público para promover ações de saneamento, o que, no Brasil, já estava consolidado desde a Constituição Federal de 1988. Em seu Art. 196, a Constituição atribui ao Estado o dever de garantir a universalidade do direito à saúde mediante "[...] políticas sociais e econômicas que visem à redução do risco de doença e de outros agravos e ao acesso universal e igualitário às ações e serviços para sua promoção, proteção e recuperação" (BRASIL, 1988, p. 1). Dentre esses serviços, encontram-se os de saneamento básico que, conforme explicado em Brasil (2004), objetivam proporcionar um ambiente salubre em determinado espaço, garantindo a saúde e o bem-estar da população beneficiada.

De acordo com Souza (2007), o acesso ao saneamento básico está relacionado a ações de promoção e de prevenção à saúde. A autora explica que o saneamento como medida preventiva tem a finalidade de interromper a transmissão de doenças e controlar fatores químicos e físicos que, de alguma forma, possam afetar a saúde das pessoas — entendida como ausência de doenças. Nesse contexto, o saneamento preventivo é baseado em ações de engenharia, como a implantação de sistemas que mantêm o ambiente limpo e salubre, garantindo o afastamento de doenças (SOUZA, 2007).

Por outro lado, o saneamento sob a perspectiva da promoção de saúde está relacionado não só à intervenção no meio físico e à sustentabilidade dos sistemas como também a um conjunto de ações voltadas para a educação sanitária e ambiental da população (SOUZA; FREITAS, 2008). Segundo os mesmos autores, o conceito de saúde nesse cenário pode ser definido como qualidade de vida, combatendo causas e determinantes da ocorrência de doenças de forma integral.

Para confirmar a relação saúde-saneamento já discutida há bastante tempo, Briscoe (1985) desenvolveu um estudo a fim de comparar as intervenções sistêmicas, como abastecimento de água e esgotamento sanitário, com as intervenções médicas, como as vacinas. O pesquisador concluiu que as intervenções sistêmicas são mais eficazes a longo prazo que as intervenções médicas, prevenindo a mortalidade e aumentando a expectativa de vida. Portanto, já na década de 80 , estudiosos evidenciavam a importância de investimentos em saneamento para garantir o bem-estar da sociedade.

Moraes (1997) explica que a ausência de saneamento adequado, especialmente com relação ao esgotamento sanitário, viabiliza a contaminação fecal do ambiente, 
comprometendo tanto o preparo e o consumo dos alimentos quanto a higiene pessoal. Desse modo, o autor afirma que essa situação cria condições favoráveis para a proliferação de vetores relacionados à diarreia. Para Esrey, Feachem e Hughes (1985), investimentos em projetos que combinem abastecimento de água, esgotamento sanitário e educação em higiene podem contribuir para a redução da taxa de morbidade por doenças diarreicas de 35 a $50 \%$.

A dengue é outra doença associada à insuficiência dos serviços de saneamento. Tauil (2001) explica que as condições de saneamento nas periferias das grandes cidades são inadequadas, principalmente quando se referem ao abastecimento de água e à coleta de lixo. Como resultado, há o aumento do número de criadouros do Aedes aegypti, principal mosquito vetor da doença. Contudo, esses problemas não são específicos da periferia, Tauil (2001) afirma que o destino inadequado (ao longo de vias públicas, praias e terrenos baldios) de recipientes em geral, como latas e copos plásticos, também favorece a proliferação do inseto transmissor.

Tauil (2002) declara que os principais desafios institucionais para combater o Aedes aegypti são atividades de vigilância sanitária, ampliação e regularização dos serviços de saneamento básico, dificuldades para inspeção predial e eliminação/tratamento de reservatórios potenciais de larvas de mosquito e atividades de informação, educação e comunicação da população. Considerando esses aspectos, Lenzi e Coura (2004) declaram que é necessário a efetiva participação do poder público para solucionar cada um desses problemas, especialmente nas áreas urbanas menos favorecidas.

Mais uma doença relacionada às más condições do saneamento é a leptospirose. Segundo Tassinari et al. (2004), a ocorrência de epidemias de leptospirose nas cidades está associada à falta de saneamento básico nos grandes centros urbanos, sobretudo na periferia, e à exposição à contaminação devido às inundações. Essas enchentes decorrem do processo de urbanização desordenado e da ineficiência dos sistemas de drenagem urbana, que é mais um problema do setor de saneamento.

Ainda no âmbito da saúde, Heller (1998) complementa que o enfoque saúde e ambiente foi consolidado no sentido de que, a saúde deve considerar o ambiente como ponto decisivo de agravos à qualidade de vida, ao mesmo tempo que se deve observar como as alterações ambientais interferem na saúde humana.

Com relação ao panorama global de saneamento, em 2015, 71\% da população global (5,2 bilhões de pessoas) teve acesso a serviços de água potável gerenciados com segurança e apenas 39\% (2,9 bilhões de pessoas) utilizaram um serviço de esgotamento sanitário seguro 
(WHO; UNICEF, 2017). O relatório ainda expõe que, no ano de 2015, 2,1 bilhões de pessoas ainda careciam de abastecimento de água adequado e 4,5 bilhões de esgotamento sanitário.

Quanto aos dados no Brasil, em 2015, 83,3\% da população brasileira possuía atendimento com rede de abastecimento de água e 50,3\% tinha acesso à coleta de esgoto (BRASIL, 2017b). Com relação ao total de esgoto coletado, 74,0\% possuía tratamento adequado, contudo, quando se considera o esgoto gerado, apenas $42,7 \%$ recebeu tratamento.

A respeito do manejo de resíduos sólidos, em 2015, a taxa de cobertura da coleta domiciliar era de $92,7 \%$ em relação à população total e de $98,6 \%$ quando considerada a população urbana (BRASIL, 2017a). Do total coletado, 60,9\% dos resíduos foram destinados a aterros sanitários, $11,5 \%$ a aterros controlados, $10,1 \%$ a lixões, 2,3\% foram encaminhados para unidades de triagem e compostagem e os 15,4\% restantes não foram declarados (BRASIL, 2017a). Percebe-se que, apesar da instituição da Política Nacional de Resíduos Sólidos, em 2010, parte dos resíduos ainda tem a sua destinação inadequada, o que pode comprometer a saúde e o bem-estar da população.

Os maiores déficits nesses serviços encontram-se nas regiões mais pobres do país e Heller (1998) explica que as condições de saneamento estão extremamente relacionadas com a desigualdade socioeconômica, em que a população menos favorecida não usufrui dos benefícios do desenvolvimento. Galvão Jr. (2009) corrobora com o exposto por Heller (1998) e enfatiza que a coleta e o tratamento de esgotos possuem o maior déficit entre os serviços de saneamento, especialmente nas zonas rurais e nas periferias dos grandes centros urbanos, afetando a qualidade de vida da população menos favorecida.

Essa desigualdade social presente no país colabora para que continuem existindo grandes áreas de pobreza com serviços precários de saneamento e saúde, o que contribui para a permanência de altos índices de mortalidade infantil e de mortalidade e morbidade por causas evitáveis, como por parasitoses intestinais e doenças diarreicas (BRASIL, 2004).

Por esses motivos, a universalização dos serviços de saneamento deve ser colocada como prioridade no âmbito das políticas públicas a fim de reduzir essas diferenças e garantir a equidade social. Heller (1998) sugere comparar indicadores de desenvolvimento com o quadro de saúde para subsidiar políticas públicas com compromisso social e, assim, promover melhorias na qualidade de vida da sociedade.

\section{MATERIAIS E MÉTODOS}


O conjunto de informações para a realização do trabalho consistiu em reunir dados sobre os indicadores demográficos, de desenvolvimento humano, de condições sanitárias e de doenças dos 10 melhores e dos 10 piores municípios brasileiros, de acordo com o Ranking do Saneamento Básico, estudo que analisa os 100 maiores municípios brasileiros em termos de população, desenvolvido anualmente pelo Instituto Trata Brasil (OLIVEIRA; SCAZUFCA; PIRES, 2017).

$\mathrm{Na}$ Tabela 1, encontram-se descritas as amostras dos municípios pesquisados, bem com sua posição no Ranking do Saneamento.

Tabela 1 - Municípios integrantes do grupo amostral dos 10 melhores e 10 piores de acordo com o Ranking de Saneamento.

\begin{tabular}{|c|c|c|c|}
\hline \multicolumn{4}{|c|}{ Ranking do Saneamento } \\
\hline \multicolumn{2}{|c|}{ Os 10 melhores } & \multicolumn{2}{|r|}{ Os 10 piores } \\
\hline Posição & Município & Posição & Município \\
\hline $1^{\circ}$ & Franca (SP) & $91^{\circ}$ & Duque de Caxias (RJ) \\
\hline $2^{\circ}$ & Uberlândia (MG) & $92^{\circ}$ & Nova Iguaçu (RJ) \\
\hline $3^{\circ}$ & São José dos Campos (SP) & $93^{\circ}$ & Várzea Grande (MT) \\
\hline $4^{\circ}$ & Santos (SP) & $94^{\circ}$ & Gravataí (RS) \\
\hline $5^{\circ}$ & Maringá (PR) & $95^{\circ}$ & Manaus (AM) \\
\hline $6^{\circ}$ & Limeira (SP) & $96^{\circ}$ & Macapá (AP) \\
\hline $7^{\circ}$ & Ponta Grossa (PR) & $97^{\circ}$ & Porto Velho (RO) \\
\hline $8^{\circ}$ & Cascavel (PR) & $98^{\circ}$ & Santarém (PA) \\
\hline $9^{\circ}$ & Londrina (PR) & $99^{\circ}$ & Jaboatão dos Guararapes (PE) \\
\hline $10^{\circ}$ & Vitória da Conquista (BA) & $100^{\circ}$ & Ananindeua (PA) \\
\hline
\end{tabular}

Fonte: Adaptado de Oliveira, Scazufca e Pires (2017).

No desenvolvimento do presente trabalho, foram utilizados dados obtidos a partir de informações contidas no Sistema Nacional de Informações sobre Saneamento (SNIS, 2016) e de estimativas de população para o ano de 2015, elaboradas pelo Instituto Brasileiro de Geografia e Estatística (IBGE, 2015).

Já a base de dados referentes aos aspectos de desenvolvimento econômico dos municípios foi obtida por meio do Atlas do Desenvolvimento Humano no Brasil 2013, elaborado pelo Programa das Nações Unidas para o Desenvolvimento (PNUD), pelo Instituto 
de Pesquisa Econômica Aplicada (IPEA) e pela Fundação João Pinheiro (FJP) (PNUD; IPEA; FJP, 2013).

Por outro lado, a caracterização do perfil de saúde foi realizada a partir de dados secundários do Departamento de Informática do Sistema Único de Saúde (SUS), DATASUS e do Ministério da Saúde (BRASIL, 2015), através da ferramenta TABNET.

As descrições dos indicadores utilizados e as fontes dos dados das variáveis explicativas que foram utilizadas nos testes estatísticos são apresentadas no Quadro 1.

\begin{tabular}{|c|c|c|c|}
\hline \multicolumn{4}{|c|}{ Características dos Municípios } \\
\hline Dimensões & Variáveis & Unidade & Fonte de Dados \\
\hline \multirow{2}{*}{$\begin{array}{l}\text { Geográfica e } \\
\text { Demográfica }\end{array}$} & Macrorregiões & N, NE, SE, S, CO & \multirow{2}{*}{$\begin{array}{c}\text { Projeção do Censo } \\
\text { Demográfico } \\
\text { (IBGE, 2015) } \\
\end{array}$} \\
\hline & População Total & Habitantes & \\
\hline \multirow{3}{*}{ Saúde } & $\begin{array}{c}\text { Taxa de internação } \\
\text { por Diarreia }^{(\mathbf{1})}\end{array}$ & \multirow{2}{*}{$\begin{array}{c}\text { internações } / 100 \text { mil } \\
\text { habitantes }\end{array}$} & \multirow{3}{*}{$\begin{array}{c}\text { DATASUS } \\
\text { (BRASIL, 2015) }\end{array}$} \\
\hline & $\begin{array}{l}\text { Taxa de internação } \\
\text { por Dengue }{ }^{(2)}\end{array}$ & & \\
\hline & $\begin{array}{l}\text { Valor Médio por } \\
\text { Internação por } \\
\text { Leptospirose }^{(3)}\end{array}$ & R\$/internação & \\
\hline Condições Sanitárias & $\begin{array}{l}\text { Índice de Esgoto } \\
\text { Tratado Referido à } \\
\text { Água Consumida }\end{array}$ & $\%$ & 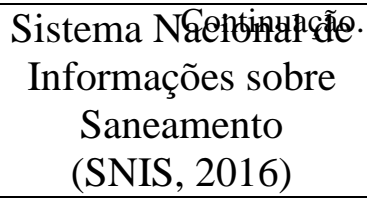 \\
\hline $\begin{array}{c}\text { Desenvolvimento } \\
\text { Humano }\end{array}$ & IDH-M ${ }^{(\mathbf{4})}$ & - & $\begin{array}{c}\text { Atlas do } \\
\text { Desenvolvimento } \\
\text { (PNUD; IPEA; FJP, } \\
\text { 2013) }\end{array}$ \\
\hline
\end{tabular}

Quadro 1 - Quadro resumo dos critérios adotados e fontes dos dados na elaboração das variáveis

${ }^{(\mathbf{1})}$ Taxa de internação por Diarreia: considerando Cólera, Febres tifoide e paratifoide, Shigelose, Amebíase, Diarreia e gastroenterite origem infecciosa presumível, Outras doenças infecciosas intestinais, no período de 2008-2015.

${ }^{(2)}$ Taxa de internação por dengue: considerando dengue [dengue clássico] e febre hemorrágica devido ao vírus da dengue, no período de 2008-2015.

${ }^{(3)}$ Valor médio por internação por leptospirose: considerando leptospirose icterohemorrágica, outras formas de leptospirose e leptospirose não especificada, no período de 2008-2015.

(4)Índice de Desenvolvimento Humano Municipal: representa a média geométrica dos índices das dimensões renda, educação e longevidade, com pesos iguais.

A compatibilização dos quatro bancos de dados foi realizada por meio de planilha eletrônica, sendo empregado como indexador o código utilizado pelo IBGE para identificação dos municípios.

As variáveis obtidas foram inicialmente testadas quanto à normalidade, homogeneidade e aderência das variâncias, utilizando os testes Shapiro-Wilk e Qui-quadrado. 
Diante da constatação de que os pressupostos da distribuição normal não se aplicaram às amostras de dados, recorreu-se a um escopo de métodos inferenciais compostos por testes não paramétricos.

Com o intuito de comparar as caraterísticas dos municípios e a sua posição no Ranking do Saneamento, foi aplicado o teste de comparação de medianas de grupos denominado de $U$ de Mann-Whitney.

Em relação à análise quantitativa das variáveis categóricas posição no Ranking do Saneamento e macrorregião, foi utilizada a ferramenta estatística do teste qui-quadrado, sendo que para verificar as associações existentes foi utilizado o teste estatístico multivariado denominado análise de correspondência.

Cabe ressaltar que todas as análises estatísticas descritivas e inferenciais foram realizadas utilizando o software Statsoft Statistica ${ }^{\circledR}$ versão 8.0, ao nível de 5\% de significância (STATSOFT, 2007).

\section{RESULTADOS E DISCUSSÃO}

Ao serem analisadas as correspondências existentes entre as posições dos municípios no Ranking do Saneamento e as macrorregiões brasileiras (Figura 1), percebe-se que as cidades mais bem classificadas estão localizadas nas regiões sul e sudeste, ao passo que, as que possuem o pior desempenho estão relacionadas às regiões norte, nordeste e centro-oeste.

Essa acentuada diferença regional indica uma priorização de investimento nos estados localizados principalmente na região sudeste, com a presença das companhias estaduais pelos planos e políticas públicas governamentais.

Além disso, Britto (2009) destaca que o atual modelo de gestão dos serviços de saneamento conserva muitas características do modelo estruturado na década de 1970, fortemente influenciado pelas diretrizes do regime militar e calcado na centralização decisória e econômica. Privilegiou-se, nos serviços de saneamento, um modelo de gestão baseado na concessão de serviços de caráter municipal para as empresas estaduais. 


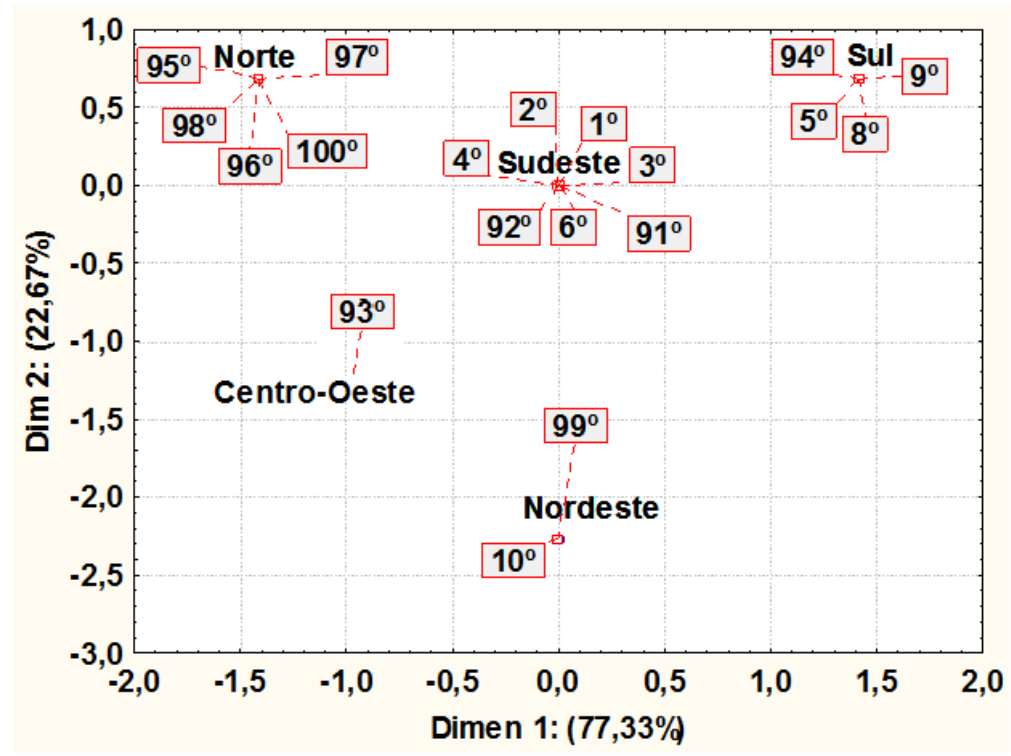

Figura 1 - Mapa perceptual das associações existentes entre as posições dos municípios no Ranking do Saneamento e as macrorregiões brasileiras.

Outro fator que chama atenção é que entre as primeiras cidades do Ranking do Saneamento encontram-se cidades localizadas no interior do Brasil, e por outro lado, entre o grupo correspondente às cidades que possuem as piores colocações, encontram-se três capitais de estado, sendo estas: Manaus (AM), Macapá (AP) e Porto Velho (RO).

Oliveira (2011) explica que os serviços de saneamento em Manaus são realizados por uma empresa privada que, atualmente, investe mais na manutenção dos sistemas já existentes do que na ampliação física dos serviços. A autora também discute sobre os valores das tarifas, que antes da privatização, seguiam os preços cobrados por outras companhias de mesmo porte, porém, após a consolidação da empresa privada, foram estabelecidas tarifas elevadas, inclusive, uma das mais altas do Brasil.

Portanto, o panorama do saneamento em Manaus pode ser explicado pelo crescimento urbano acelerado e desordenado, pelos baixos investimentos no setor e pela falta de condições financeiras da população para bancar os altos custos com as tarifas. Oliveira (2011) relata que o município encontra-se em um quadro de exclusão aos serviços de saneamento, o que contribui para a ocorrência de elevados índices de doenças gastrointestinais.

Com relação à Macapá, Oliveira e Moraes (2017) ressaltam que o município sofreu um crescimento populacional acelerado, desordenado e em curto espaço de tempo, o que contribui para o atual quadro precário do setor de saneamento. Os autores comentam que os baixos índices de coleta e tratamento de esgotos podem contaminar as águas superficiais e subterrâneas, o que pode comprometer a qualidade dos poços rasos, forma de abastecimento 
comum em área que não tem acesso à rede de abastecimento de água. Segundo Oliveira e Moraes (2017) a consequência dessa situação é a maior incidência de doenças de veiculação hídrica.

Os mesmos autores relatam que, atualmente, o sistema de abastecimento de água encontra-se antigo e deteriorado, apresentando problemas de rompimentos e vazamentos. Nesse sentido, verifica-se a necessidade da reabilitação das redes mais antigas e da ampliação do sistema para atender novas áreas, o que só será possível a partir de políticas públicas bem planejadas (OLIVEIRA; MORAES, 2017).

O quadro de Porto Velho não é diferente do de Manaus e Macapá. Segundo Barroso, Cherubini e Cordeiro (2005), o município cresceu de forma acelerada e desordenada devido aos incentivos do governo federal nas décadas de 70 e 80, resultando em problemas ambientais e de infraestrutura urbana e rural. Devido ao crescimento desenfreado e à ineficácia das políticas públicas, até hoje a região possui baixos níveis socioeconômicos e passa por impasses relacionados à saúde pública.

Na Figura 2, encontram-se expostos os resultados referentes aos gráficos box-plot e os resumos dos testes estatísticos da posição no Ranking do Saneamento em função das características dos municípios.

Quando analisada a quantidade de habitantes entre os dois grupos de municípios (Figura 2 (a)), verifica-se que não existem diferenças estatisticamente significativas entre os portes populacionais. Dessa forma, por se tratarem de inferências realizadas dentro dos 100 maiores municípios brasileiros, pode-se confirmar a homogeneidade populacional, e com isso, são excluídos os casos (pequenos municípios) em que a prestação dos serviços não são atrativas em termos de quantidade de potenciais usuários, ou seja, formação de economia de escala ${ }^{1}$.

Assim, outros fatores intrínsecos ao município podem contribuir para a acentuada diferença de desempenho em termos sanitários, como a priorização de políticas públicas que preferem determinada região, ou até mesmo fatores culturais.

Em termos populacionais (Figura 2 (a)), constata-se que os 10 piores municípios apresentam uma população acima de 6,7 milhões de habitantes, porém, mais de 5,2 milhões

\footnotetext{
${ }^{1}$ Por ser considerado um monopólio natural, a prestação dos serviços de saneamento, como apontam as teses de alguns autores como Nauges e Berg (2008); Abbott e Cohen (2009); Campos (2010); Lentini e Mercadier (2014), e a atuação das prestadoras dos serviços de saneamento ocorrem tendo em vista a formação de economias de escala e densidade, em que os custos médios de longo prazo diminuem ao aumentar a produção, tornando as empresas maiores mais eficientes que as menores, o que pode representar, para o prestador, maior retorno econômico.
} 
de pessoas não possuem coleta dos esgotos $(77,68 \%)$, e, metade desses municípios tratam apenas 7,91\% do total de esgotos gerados em relação à quantidade de água consumida (Figura $2(b))$.

Por outro lado, nas 10 melhores cidades a população é de aproximadamente 4,3 milhões e somente cerca de 142 mil $(3,25 \%)$ não possuem acesso à coleta dos esgotos e metade desses apresentam o índice de esgoto tratado referido à água consumida de 91,78\% (Figura $2(b)$ ).

Com relação ao IDH-M (Figura 2 (c)), nota-se que o valor encontrado de 0,784 para as 10 melhores cidades é estatisticamente superior ao das 10 piores $(0,717)$, o que permite inferir que as 10 melhores — com relação às condições de saneamento — apresentam condições de qualidade de vida e de desenvolvimento econômico superiores quando comparadas às 10 piores.

Quando analisados os dados de forma individualizada, verifica-se que os municípios integrantes do grupo que apresenta o melhor desempenho no Ranking do Saneamento, possuem os IDH-M classificados como alto a muito alto $(0,700$ a 1,000$)$. Já no outro grupo, que estão classificados os municípios com os piores desempenhos, são encontradas situações em que o IDH-M é classificado como médio, como é o caso da cidade de Santarém/PA $(0,691)$.

Portanto, comparando os dados de coleta e tratamento de esgotos com as informações sobre o IDH-M (Figura 2 (b) e (c)), verifica-se que o acesso à provisão adequada de água e ao tratamento de esgoto podem estar relacionadas às melhores condições socioeconômicas e de qualidade de vida.

No âmbito da saúde e saneamento (Figura 2 (d); (e) e (f)), foram analisadas as taxas de internação por diarreia e por dengue (internações/100 mil habitantes) e o valor médio por internação por leptospirose (R \$internação).

Para os casos de diarreia, observa-se que os 10 piores municípios têm uma taxa de 112 internações/100 mil habitantes, enquanto que para os 10 melhores, essa taxa corresponde a 35 (Figura 2 (d)). Quanto à dengue, a taxa de internação das 10 melhores cidades é de 8,12 internações/100 mil habitantes e a das 10 piores é de 27,59 (Figura (e)). Portanto, nota-se que as taxas de internação, tanto para a diarreia quanto para a dengue, são maiores nos municípios que apresentam piores condições de saneamento. Esse resultado corrobora com o já exposto por Moraes (1997) e Tauil (2001). 
ROCHA, A. C. T.; ROSSONI, H. A.V.; FARIA, M. T. da S. Determinantes envolvidos no perfil de doenças relacionadas às condições sanitárias inadequadas nos municípios brasileiros: avaliação realizada nas 10 melhores e 10 piores cidades do ranking do saneamento

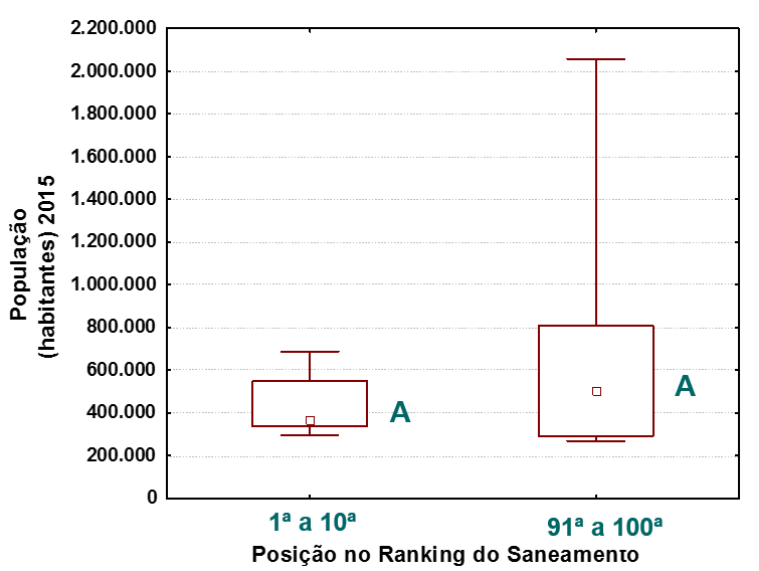

(a)

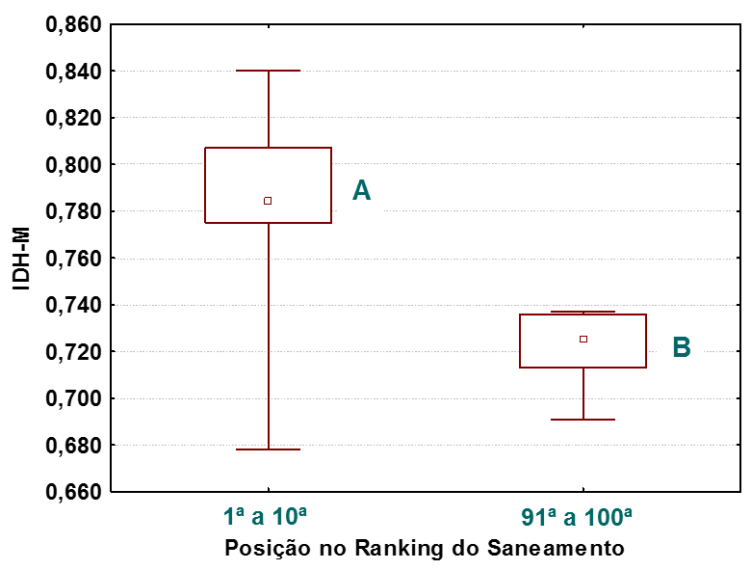

(c)

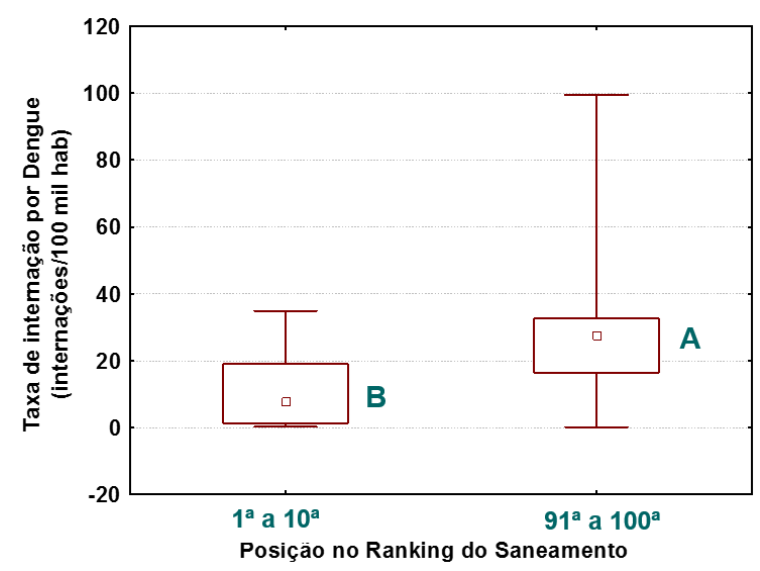

(e)

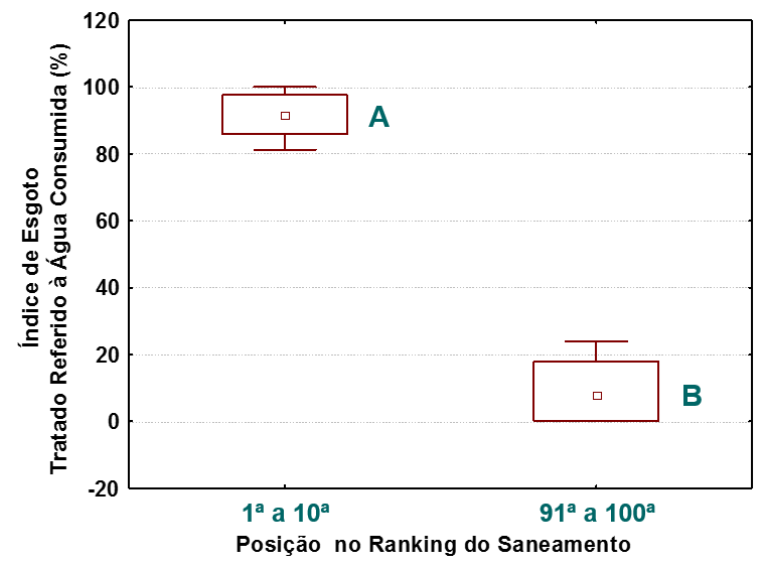

(b)

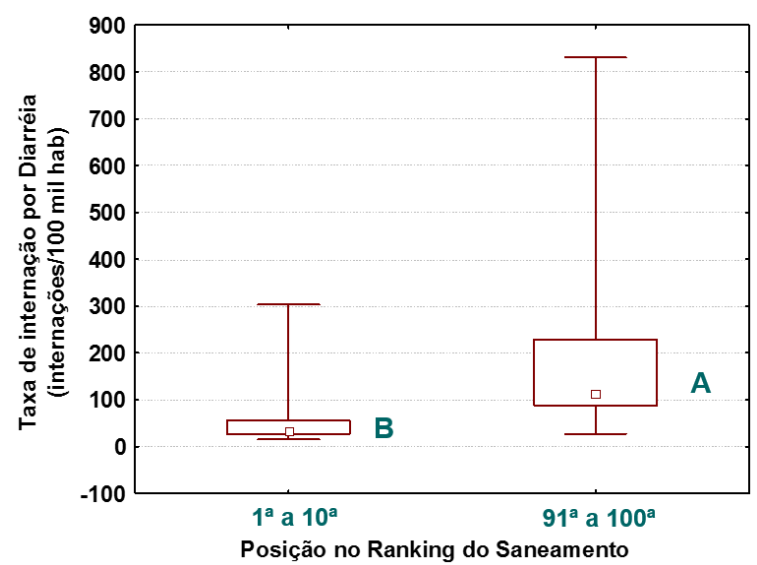

(d)

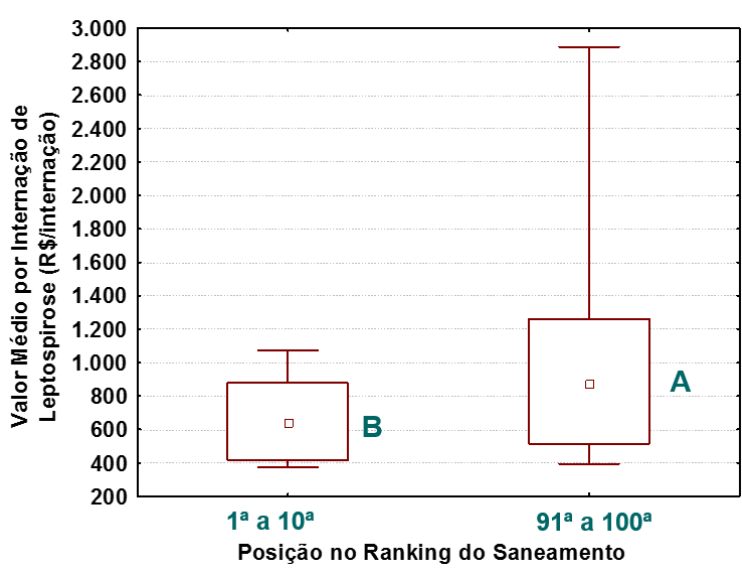

(f)

Legenda: Gráficos box-plot: Md: mediana; $25 \%=1^{\circ} Q_{(1 / 4):}$ primeiro quartil; $75 \%=$ $\mathbf{3}^{\circ} \mathbf{Q}_{(3 / 4)}$ : terceiro quartil; Máx.: valor máximo e Mín.: valor mínimo

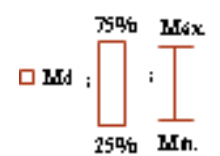

Conclusão: *significativo para o teste não paramétrico Kruskal-Wallis (valor-p $=0,000$ ) e \#Posições no ranking seguidas pela mesma letra não diferem estatisticamente $(\alpha=$ $0,05)$ entre si.

Figura 2 - Gráficos box-plot e resumo dos testes estatísticos da posição no Ranking do Saneamento em função das características dos municípios: (a) População total; (b) Índice de Esgoto Tratado Referido a Água Consumida (\%); (c) IDH-M; (d) Taxa de internação por Diarreia (internações/100 mil habitantes); (e) Taxa de internação por Dengue (internações/100 mil habitantes); e (f) Valor Médio por Internação por Leptospirose (R\$/internação). 
Por fim, o valor por internação por leptospirose corresponde a $\mathrm{R} \$ 875,40$ no caso dos 10 piores municípios e a $\mathrm{R} \$ 641,88$ para os 10 melhores municípios (Figura (f)). Dessa forma, percebe-se claramente que o valor gasto com as internações é inferior nas 10 melhores cidades, reafirmando, com isso, que investimentos em saneamento reduzem os custos na área de saúde pública.

Além disso, conforme aponta estudo realizado pela Instituto Trata Brasil (2017), a falta de saneamento básico nas cidades pode afetar a economia nacional por reduzir a produtividade do trabalhador, impactar o aprendizado de crianças e jovens, além de afastar o interesse turístico de regiões que sofrem com o despejo de esgoto e ausência de água encanada.

\section{CONCLUSÕES}

Os resultados encontrados neste trabalho indicaram uma discrepância regional em relação ao acesso aos serviços de saneamento básico, demonstrando que os municípios mais bem classificados no Ranking do Saneamento estão localizados nas regiões sul e sudeste, que são as mais desenvolvidas do Brasil. Notou-se também que as 10 melhores cidades possuem melhor qualidade de vida e maior desenvolvimento econômico, dados evidenciados pelo valor do IDH-M.

Nos aspectos ligados à saúde, observou-se que os baixos índices de saneamento, principalmente os que se referem ao esgotamento sanitário, estão fortemente associados àqueles municípios com maiores índices epidemiológicos (diarreia, dengue e leptospirose). Desse modo, percebe-se que a falta ou a existência de serviços de saneamento inadequados provocam a insalubridade ambiental que, por sua vez, favorece a ocorrência de diversas doenças. Nesse sentido, pode-se reafirmar a relação entre saúde, saneamento e ambiente, já defendida por diversos autores, como Souza (2007).

A partir da realização deste trabalho, concluiu-se que, mesmo após 10 anos da Política Nacional de Saneamento Básico, a universalização dos serviços de saneamento ainda está distante de ser alcançada, refletindo na saúde e no bem-estar na população. Destaca-se que esse estudo considerou os maiores municípios brasileiros, logo, os resultados podem ser ainda piores nas pequenas cidades. Assim, verifica-se a necessidade de investimentos adequados e políticas públicas eficazes para garantir, de forma igualitária, uma melhor qualidade de vida para a sociedade. 


\title{
DETERMINANTS INVOLVED IN THE PROFILE OF DISEASES RELATED TO INDEQUATE SANITARY CONDITIONS IN BRAZILIAN MUNICIPALITIES: EVALUATION CARRIED OUT IN THE 10 BEST AND 10 WORST CITIES OF THE SANITATION RANKING
}

\begin{abstract}
The objective of the present study was to analyze demographic, human development, sanitary conditions and disease profiles - diarrhea, dengue and leptospirosis -, highlighting the 10 best and 10 worst municipalities, according to the Sanitation Ranking developed by the Instituto Trata Brasil. For that, data obtained by the compatibility of information from the Sistema Nacional de Informações sobre Saneamento, the Censo Demográfico and the Departamento de Informática do Sistema Único de Saúde, referring to the year 2015 and the Atlas do Desenvolvimento Humano, referring to the year of 2013. It was verified, through univariate and multivariate non-parametric statistical tests, that the municipalities ranked highest in the ranking are located in the south and southeast regions, which are the most developed in Brazil. In addition, it was also noted that the 10 best ranked cities in the Sanitation Ranking have a better quality of life and greater economic development, data evidenced by the value of the Municipal Human Development Index. In terms of health, it was observed that the 10 worst municipalities are strongly associated with the north and northeast regions and present poor performance in the sanitation indicators, especially those associated to the indices related to the proportion of treated sewage referred to water consumed and to the epidemiological indices - diarrhea, dengue and leptospirosis. In this way, it is perceived that the lack or the existence of inadequate sanitation services provoke the environmental insalubrity that, in turn, favor the occurrence of several diseases.
\end{abstract}

Keywords: Sanitation. Public policy. Sanitation Ranking.

\section{REFERÊNCIAS}

ABBOTT, M.; COHEN, B. Productivity and efficiency in the water industry. Utilities Policy, Guildford, v. 17, p. 233-244, 2009.

ALMEIDA, L. M.; VERMELHO, L. L. Projeto de avaliação dos impactos do programa de despoluição da Baía de Guanabara sobre as condições de saúde e qualidade de vida "PAISQUA" - apresentação da situação atual. In: HELLER L. et al. (Org.). Saneamento e saúde nos países em desenvolvimento. Rio de Janeiro: CC\&P Editores, 1997. p. 36-48.

BARROSO, M. M.; CHERUBINI, K. V.; CORDEIRO, J. S. Análise crítica da sustentabilidade ambiental, saneamento e saúde pública no município de Porto Velho. In: CONGRESSO BRASILEIRO DE ENGENHARIA SANITÁRIA E AMBIENTAL, 23., 2005, Campo Grande. Anais... Campo Grande: ABES, 2005.

BRASIL. Constituição (1988). Constituição da República Federativa do Brasil, 1988.

Brasília: Senado Federal, Centro Gráfico, 1988. Disponível em:

<http://www.planalto.gov.br/ccivil_03/constituicao/constituicaocompilado.htm>. Acesso em: 30 out. 2017. 
Lei n. 6.938, de 31 de agosto de 1981. Dispõe sobre a política nacional do meio ambiente, seus fins e mecanismos de formulação e aplicação, e dá outras providências. 1981. Disponível em: <http://www.planalto.gov.br/ccivil_03/leis/16938.htm>. Acesso em: 30 out. 2017.

Lei n. 8.080, de 19 de setembro de 1990. Dispõe sobre as condições para a promoção, proteção e recuperação da saúde, a organização e o funcionamento dos serviços correspondentes e dá outras providências. 1990. Disponível em: <http://www.planalto.gov.br/ccivil_03/leis/L8080.htm>. Acesso em: 30 out. 2017.

Lei n. 9.433 de 8 de janeiro de 1997. Institui a política nacional de recursos hídricos, cria o sistema nacional de gerenciamento de recursos hídricos, regulamenta o inciso XIX do art. 21 da Constituição Federal, e altera o art. $1^{\circ}$ da Lei n. 8.001, de 13 de março de 1990, que modificou a Lei n. 7.990, de 28 de dezembro de 1989. 1997. Disponível em: <http://www.planalto.gov.br/ccivil_03/leis/19433.htm>. Acesso em: 30 out. 2017.

Lei n. 11.445, de 05 de janeiro de 2007. Estabelece diretrizes nacionais para o saneamento básico. 2007. Disponível em: <http://www.planalto.gov.br/ccivil_03/_ato20072010/2007/lei/l11445.htm>. Acesso em: 30 out. 2017.

Ministério da Saúde. Organização Pan-Americana da Saúde. Avaliação de impacto na saúde das ações de saneamento: marco conceitual e estratégia metodológica. Brasília: Ministério da Saúde, 2004.

Ministério da Saúde. Plano nacional de saúde e ambiente no desenvolvimento sustentável: diretrizes para implementação. Brasília: Ministério da Saúde. 1995. Disponível em: 〈http://bvsms.saude.gov.br/bvs/publicacoes/Planonac.pdf>. Acesso em 30 out. 2017.

. Ministério da Saúde. Portal da Saúde: informações de saúde (TABNET). Brasília, c2008. Disponível em: <http://tabnet.datasus.gov.br/>. Acesso em 12 mar. 2017.

Ministério das Cidades. Secretaria Nacional de Saneamento Ambiental. Sistema Nacional de Informações sobre Saneamento. Diagnóstico do manejo de resíduos sólidos urbanos - 2015. Brasília: MCIDADES/SNSA, 2017a. 173 p.

Ministério das Cidades. Secretaria Nacional de Saneamento Ambiental. Sistema Nacional de Informações sobre Saneamento. Diagnóstico dos serviços de água e esgotos 2015. Brasília: MCIDADES/SNSA, 2017b. 212 p.

BRISCOE, J. Evaluating water supply and other health programs: short-run vs long-run mortality effects. Public Health, London, v. 99, n. 3, p. 142-145, 1985.

BRITTO, A. L. Gestão regionalizada e consórcios públicos: perspectivas para cooperação intermunicipal e gestão integrada das águas em áreas metropolitanas. In: BRASIL. Ministério das Cidades. Secretaria Nacional de Saneamento Ambiental. Instrumentos das políticas e da gestão dos serviços públicos de saneamento básico. Brasília: MCIDADES/SNSA, 2009. p. 131-146.

CAMPOS, F. M. Economias de escala e ineficiência técnica: a importância da dimensão de operação das concessionárias estaduais de água e esgoto brasileiras (1998-2008). In: 
ENCONTRO NACIONAL DE ECONOMIA, 38., 2010, Salvador. Anais... Salvador: ANPEC, 2010. p. 1-17.

COSTA, S. S. et al. Indicadores epidemiológicos aplicáveis a estudos sobre a associação entre saneamento e saúde de base municipal. Engenharia Sanitária e Ambiental, Rio de Janeiro, v. 10, n. 2, p. 118-127, abr./jun. 2005.

CYNAMON, S. E. Política de saneamento: proposta de mudança. Cadernos de Saúde Pública, Rio de Janeiro, v. 2, n. 2, p. 141-149, abr./jun. 1986.

ESREY, S. A.; FEACHEM, R. G.; HUGHES, J. M. Interventions for the control of diarrhoeal diseases among young children: improving water supplies and excreta disposal facilities.

Bulletin of the World Health Organization, New York, v. 4, n. 63, p. 757-772, 1985.

GALVÃO JR., A. C. Desafios para universalização dos serviços de água e esgoto no Brasil.

Revista Panamericana de Salud Pública, Washington, v. 25, n. 6, p. 548-56, jun. 2009.

HELLER, L. Relação entre saúde e saneamento na perspectiva do desenvolvimento. Ciência \& Saúde Coletiva, Rio de Janeiro, v. 3, n. 2, p. 73-84, 1998.

HELLER, L.; CASTRO, J. E. Política pública de saneamento: apontamentos teóricoconceituais. Engenharia Sanitária e Ambiental, Rio de Janeiro, v. 12, n. 3, p. 284-295, jul./set., 2007.

INSTITUTO BRASILEIRO DE GEOGRAFIA E ESTATÍSTICA (IBGE). Estimativas populacionais para os municípios e para as Unidades da Federação brasileiros em 01.07.2015. Rio de Janeiro, 2015. Disponível em:

<https://ww2.ibge.gov.br/home/estatistica/populacao/estimativa2015/default.shtm>. Acesso em: 20 fev. 2017.

INSTITUTO TRATA BRASIL. Benefícios econômicos e sociais da expansão do saneamento no Brasil. [S.1.] : Ex Ante Consultoria Econômica, 2017. Disponível em: <https://www.tratabrasil.org.br/datafiles/estudos/beneficios-ecosocio/relatorio-completo.pdf >. Acesso em: 03 nov. 2017.

LENTINI, E. J.; MERCADIER, A. C. Efficiency in Brazil water and sanitation sector and its relationship with regional provision, property and the independence of operators. Utilities Policy, Guilford, v. 28, p. 42-51, 2014.

LENZI, M. F.; COURA, L. C. Prevenção da dengue: a informação em foco. Revista da Sociedade Brasileira de Medicina Tropical, Uberaba, v. 37, n. 4, p. 343-350, jul./ago. 2004.

LEONETI, A. B.; PRADO, E. L.; OLIVEIRA, S. V. W. B. Saneamento básico no Brasil: considerações sobre investimentos e sustentabilidade para o século XXI. Revista de Administração Pública, Rio de Janeiro, v. 45, n. 2, p. 331-348, 2011.

MORAES, L. R. S. Avaliação do impacto sobre a saúde das ações de saneamento ambiental em áreas pauperizadas de Salvador - Projeto AISAM. In: HELLER L. et al. (Org.).

Saneamento e saúde nos países em desenvolvimento. Rio de Janeiro: CC\&P Editores, 1997. p. 281-305. 
NAUGES, C.; BERG, C. Economies of density, scale and scope in the water supply and sewerage sector: a study of four developing and transition economies. Journal of Regulatory Economics, Dordrecht v. 34, p. 144-163, 2008.

OLIVEIRA, C. F. Água e saneamento básico em Manaus, Amazonas - Brasil: valoração econômica em serviços de utilidade pública. Geografia em Questão, Cascavel, v. 4, n. 2, p. 181-196, 2011.

OLIVEIRA, G.; SCAZUFCA, P.; PIRES, R. C. Ranking do saneamento: Instituto Trata Brasil: 2017. São Paulo: GO Associados, 2017.

OLIVEIRA, O. C.; MORAES, S. C. Desafios para a sustentabilidade na gestão dos serviços de abastecimento de água na Amazônia: aspectos socioambientais e econômicos do sistema de abastecimento de água na cidade de Macapá-AP. Espacios, Caracas, v. 38, n. 22, p. 27-38, 2017.

PROGRAMA DAS NAÇÕES UNIDAS PARA O DESENVOLVIMENTO (PNUD); INSTITUTO DE PESQUISA ECONÔMICA APLICADA (IPEA); FUNDAÇÃO JOÃO PINHEIRO (FJP). Atlas do desenvolvimento humano no Brasil: dados brutos. Ano base 2013. Arquivo (29,73 Megabytes). Arquivo Excel 2007. Disponível em: <http://www.atlasbrasil.org.br/2013/pt/download/>. Acesso em: 20 fev. 2017.

SAIANI, C. C. S.; TONETO JR., R. Evolução do acesso a serviços de saneamento básico no Brasil (1970 a 2004). Economia e Sociedade, Campinas, v. 19, n. 1, p. 79-106, abr. 2010.

SCHERMBRUCKER, Karin. Every dollar invested in water, sanitation brings four-fold return in costs - UN. UN News, [New York], 19 nov. 2014. Disponível em: <http://www.un.org/apps/news/story.asp?NewsId=49377\#.WfnEVY9SzIX>. Acesso em: 01 nov. 2017.

SISTEMA NACIONAL DE INFORMAÇÕES SOBRE SANEAMENTO (SNIS). MINISTÉRIO DAS CIDADES. Diagnóstico dos serviços de água e esgotos - 2015. 2016. Disponível em: <http://www.snis.gov.br/diagnostico-agua-e-esgotos/diagnostico-ae-2015 > Acesso em: 20 fev. 2017.

SOUZA, C. M. N. Relação saneamento-saúde-ambiente: os discursos preventivistas e da promoção da saúde. Saúde e Sociedade, São Paulo, v. 16, n. 3, set./dez. 2007.

SOUZA, C. M. N.; FREITAS, C. M. O saneamento na ótica de profissionais de saneamentosaúde-ambiente: promoção da saúde ou prevenção de doenças? Engenharia Sanitária e Ambiental, Rio de Janeiro, v. 13, n. 1, p. 45-63, jan./mar. 2008.

STATSOFT. Statistica (data analysis software system). Version 8.0. Tulsa: StatSoft, 2007. 1 CD-ROM.

TASSINARI, W. S. et al. Distribuição espacial da leptospirose no município do Rio de Janeiro, Brasil, ao longo dos anos de 1996-1999. Cadernos de Saúde Pública, Rio de Janeiro, v. 20, n. 6, p. 1721-1729, nov./dez. 2004. 
TAUIL, P. L. Aspectos críticos do controle do dengue no Brasil. Cadernos de Saúde Pública, Rio de Janeiro, v. 18, n. 3, p. 867-871, maio/jun. 2002.

TAUIL, P. L. Urbanização e ecologia do dengue. Cadernos de Saúde Pública, Rio de Janeiro, v. 17, p. 99-102, 2001. Suplemento.

TONETO JR., R.; SAIANI, C. C. S. Restrições à expansão dos investimentos no saneamento básico brasileiro. Revista Econômica do Nordeste, Fortaleza, v. 37, n. 4, p. 572-591, out./dez. 2006.

TUROLLA, F. A. Política de saneamento básico: avanços recentes e opções futuras de políticas públicas. Texto para Discussão, Brasília, DF, n. 922, p. 1-26, dez. 2002.

UNITED NATIONS (UN). A/HRC/36/45. Report of the Special Rapporteur on the human rights to safe drinking water and sanitation. New York, 2017. 20 p. Disponível em: $<$ https://documents-ddsny.un.org/doc/UNDOC/GEN/G17/216/95/PDF/G1721695.pdf?OpenElement>. Acesso em 30 out. 2017.

Resolution A/RES/64/292. The human right to water and sanitation. General Assembly. New York, 2010. 3 p. Disponível em: <http://www.un.org/es/comun/docs/?symbol=A/RES/64/292\&lang=E >. Acesso em: 30 out. 2017.

WORLD HEALTH ORGANIZATION (WHO); UNITED NATIONS CHILDREN'S FUND (UNICEF). Progress on drinking water, sanitation and hygiene: 2017: update and SDG baselines. 2017. Licence: CC BY-NC-SA 3.0 IGO.

\section{DADOS DOS AUTORES}

\section{Ana Carolina Toledo Rocha}

E-mail: anacarolinatoledorocha@gmail.com Currículo Lattes: http://lattes.cnpq.br/1569088682564879

Engenheira Ambiental pela Universidade Federal de Itajubá (Unifei) - Campus Itabira. Mestre em Sustentabilidade e Tecnologia Ambiental pelo Instituto Federal de Minas Gerais (IFMG) Campus Bambuí.

\section{Hygor Aristides Victor Rossoni}

E-mail: rossoni@ufv.br

Currículo Lattes: http://lattes.cnpq.br/5963315112031411

Engenheiro Ambiental pela Universidade Federal de Viçosa (UFV) - Campus Viçosa. Mestre em Ciência Florestal pela UFV - Campus Viçosa. Doutor em Saneamento, Meio Ambiente e Recursos Hídricos pela Universidade Federal de Minas Gerais (UFMG). Professor da UFV Campus Florestal e membro permanente do corpo docente e orientador do mestrado profissional em Sustentabilidade e Tecnologia Ambiental do Instituto Federal de Minas Gerais (IFMG) - Campus Bambuí. 


\section{Marco Túlio da Silva Faria}

E-mail: marcotuliodefaria@gmail.com

Currículo Lattes: http://lattes.cnpq.br/1077303391317030

Tecnólogo em Gestão Ambiental pela Universidade Federal de Viçosa (UFV) - Campus Florestal. Engenheiro Ambiental pelo Centro Federal de Educação Tecnológica de Minas Gerais (CEFET-MG). Mestre em Saneamento, Meio Ambiente e Recursos Hídricos pela Universidade Federal de Minas Gerais (UFMG). 